Open Scientist Handbook • OSH

\title{
The Work of Culture in \\ Your Open Science \\ Organization
}

Bruce R. Caron

Published on: Mar 03, 2021

DOI: $10.21428 / 8 b b b 7 f 85.95887 c c d$

License: Creative Commons Attribution 4.0 International License(CC-BY 4.0). 


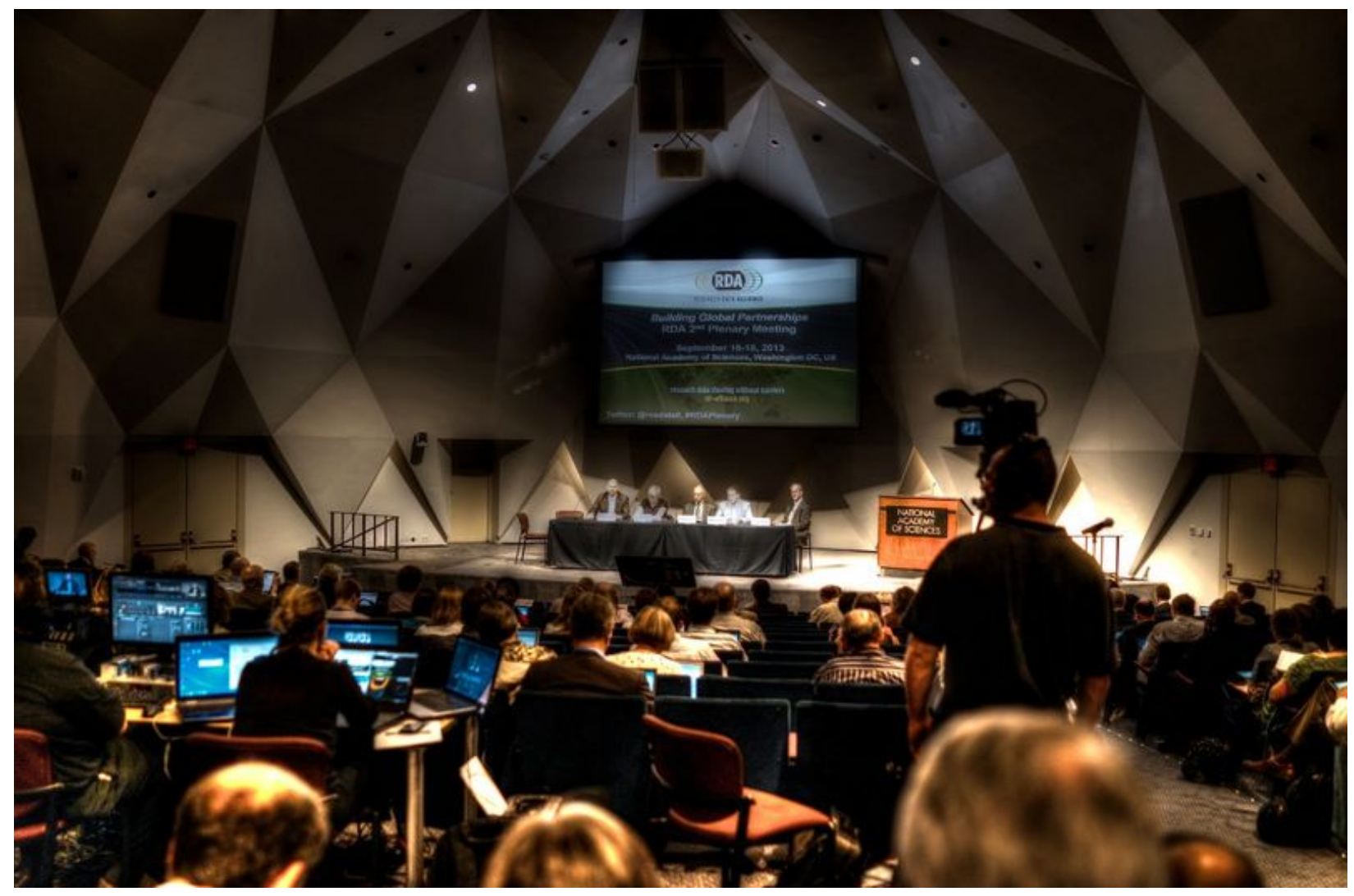

"Religion is a culture of faith; science is a culture of doubt" Richard Feynman (unsourced).

"Don't think of culture as other than accumulated learning that sits inside you as one of your layers of consciousness" (Edwin Schein 2016; Accessed April 4, 2019).

“'Culture' is everything we don't have to do" (Brian Eno 1996; W Magazine)

\section{All the culture that fits: exploring the work of culture to prepare to change it}

We want culture in the academy to work for us, instead of against us. The many meanings of the word "culture" - each with certain claims to capture essential aspects of this spectrum of human proclivity and activity - make the task of outlining a notion of the "work of culture" also a chore of definitions. What is it about culture that can be said to do work? And what work is important for open science? 
One goal of this book is to help scholars who have little or no background in the academic study of culture to gain a sufficient purchase on this notion to become confident, productive agents of culture change for their home institutions, their professional associations and research organizations, and for the academy as a global science endeavor. Like quantum mechanics and machine intelligence, the serious study of culture is not one of these "dip your toes in the shallow end" kind of endeavor. However, with a roadmap through just enough of this contested space, even tenured chemistry professors (or pick your discipline) can become bonafide organizational culture-change agents.

\section{Getting back to basics}

Beginning anthropology classes might spend a month covering the "history of the anthropological ideas of culture." These notions developed first through colonial excursions, and then with missionaries and colonial settlers, and finally ethnographers. A recent (2017) online book for teaching anthropology in community colleges has distilled culture down to a few pages, entitled "The Culture Concept"; Accessed April 4 , 2019.) Courses on "organizational culture" are now required in MBA curricula and iSchools.

Arjo Klamer (2017), a Dutch economist, introduces culture to his economics class by adding two meaning domains for this word: culture as the accomplishments of a society (e.g., baroque style as a form of European culture), and culture as creative activity within sectors of the economy (the arts, architecture, music, etc.). His first meaning gives us the adjective "cultured," applied to individuals who exemplify a certain noticeable style; while his second is where you go to when you click on the "culture" link in an online magazine or newspaper. 
Culture

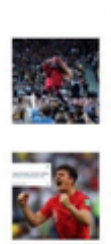

What's New

The ultimate guide to picking your person
song of the summer

al 1 hour ago

gland tan gets soccer hischest after making Twitter promise

al thourape 2. Justin Timberlake just got

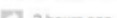

\section{Q.1. Meet the YouTuber who's} been making musical instruments out of produce for ill years 래 21 hours ago

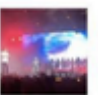

Corillaz show cut short after Del the Funky dramatic fall off stage

[a] 23 hours ago

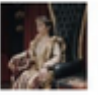

The first queen of Medieval Times' is alidey

How Drew Gooden rebuilt his online identity after Cil 2 doys ago

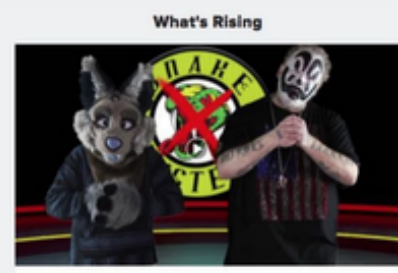

Insane Clown Posse's Violent $\mathrm{J}$ is real mad he got ripped off buying a cheap furry suit

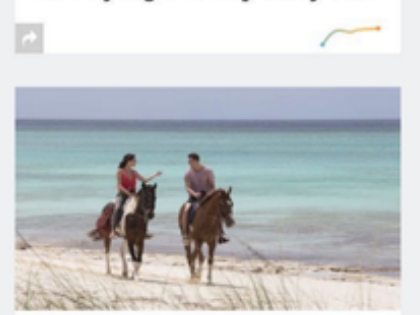

'The Bachelorette' was interrupted by Trump's SCOTUS pick. No, viewers were not fine.

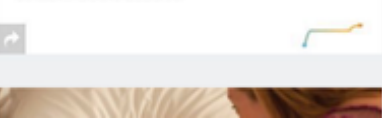

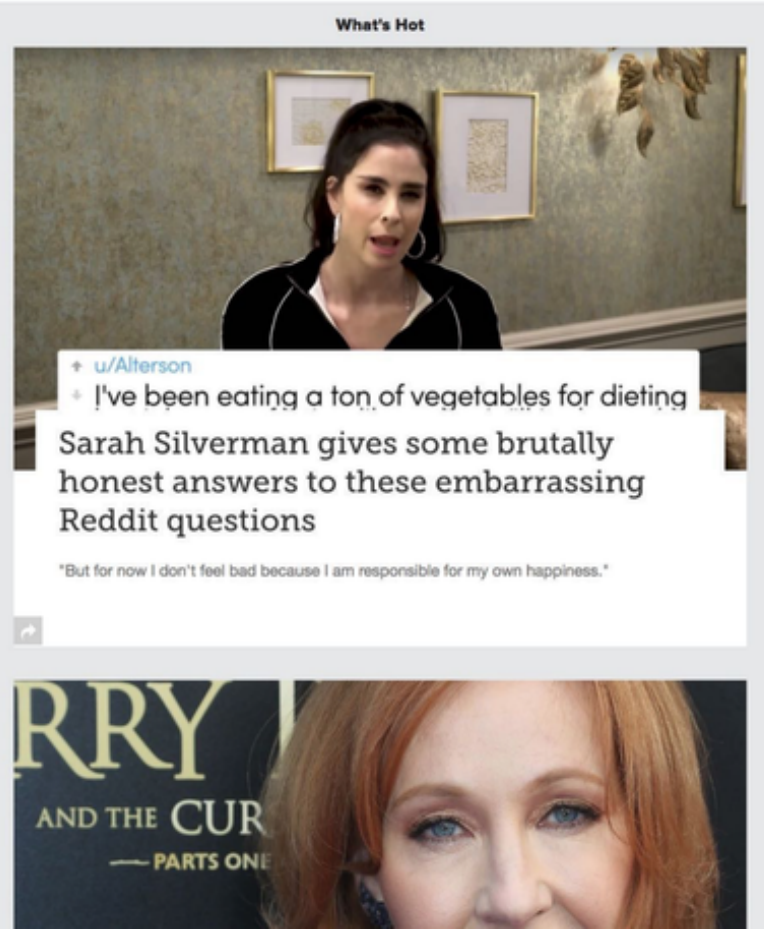

"Culture" is a section in your newspaper/magazine/webzine

\section{Culture as a process}

Folks who want to use culture and culture change as a resource or a tool to change social groups describe culture as a process. They then offer a method to intercept and guide this process (Marcus and Conner 2014). Organizational management researchers are full of advice on the culture of organizations, but usually fail to look at how this type of culture fits into the larger sense of culture's role in society or in individual identity. Anthropologists describe cultures and how these change without intervention, but little advice on how to intentionally change this. Here, you will find both anthropological and organizational perspectives, just so you are fully comfortable that you've travelled the entire landscape of the term "culture."

\section{Do you own your culture, or does your culture own you?}

"Culture is public because meaning is" (Geertz 1973).

Much of the disputed territory for culture, whether as an object of study, or as a field for intentional change, is centered on how culture is carried more or less unconsciously by the individual. Sometimes it feels as though we've been "marinated" in cultural practices our entire lives: language, cuisine, music, art, and now online 
content. There is a part of culture that is tacit, embodied, unspoken, and nonconscious. Culture theories tell us this, and they are not wrong. This aspect of culture is often used to demonstrate how difficult it is to manage culture.

\section{A vague, squishy word, indeed}

Jean-Louis Gassée (not an anthropologist; but rather of Apple, BeOS, and Palm fame), in a blog about Intel's "toxic culture" writes:

"Our powerful human emotions are bundled into something we call Culture, itself a vague, squishy word......Culture develops within us in a manner similar to our taste buds: Our gustatory education starts with Mother's milk and accumulates over time. The trouble with our acquired tastes, particularly in the realm of ideas, is that they drop below our consciousness: Raw data are filtered, judged, and labeled before being passed to our conscious, 'rational' processes."

Gassée is pointing out that parts of the repertoire of shared meanings, behaviors, and sentiments that people would label "cultural" are known without any explicit knowledge of how and when we came to know these; and even less ability to describe them.

Schein (2010) calls this a cultural "layer." This layer is learned from birth at home, and then in school, and then in the workplace, where the same tacit layer proves the hardest part to change. When your company/university/agency is running on a tacit culture layer, instead of on a reflexive intentional culture layer, it is most vulnerable to becoming toxic.

\section{Science is a reflexive, interrogative activity}

Fortunately, the main aspects of academy culture we are hoping to change can all be made explicit and available to reflexive rebooting. In fact, open science is not reinventing science as much as clearing away the extraneous cultural underbrush (such as journal impact factors) that has collected in the past half-century or so. Scientists can openly interrogate these practices, and collectively move away from perverse incentives, conflicts of interest, and culturally-supported bad behavior in the academy. The leading advice to Silican Valley CEOs today is to avoid "f*cking up your culture” (See also: Don't F*ck Up Your Culture; Accessed May 17, 2019). The academy might want to listen here. 


\section{You cannot really avoid culture if you want change}

A good point is worth saying twice: you may be an open-science pioneer who is eager and intent to bring productive changes to the academy, and yet still be uncomfortable with the notion of culture. You might prefer to offer solutions (e.g., coercive rules enforced by governments and funding organizations, novel technology platforms, and manifestos - so many manifestos) that, you hope, would shape "social behavior" without needing to confront or even consider culture. You look at the term "culture" and see a morass of competing meanings, with tangled and complex implications for the use of the term. How do you defend a program to change culture when you can't get any three people in a room to agree on what culture means?

Scientists are many things. Each of these things have something in common: a desire for precision. The "vague, squishy" term "culture" offers very little precision and a whole load of ambiguity and complexity. As a scientist, you already have your hands full of ambiguity and complexity; you are striving to understand the inherent, emergent complexity of the universe. You rely on instruments that achieve ever-better accuracy and precision to help you extract some level of near-certainty to observe your object of study.

Many scientists are dismayed by the sheer amount of fuzziness surrounding the notion of culture. So the project at hand is to un-fuzzy that corner of culture where the academy can work on intentional changes to promote open science. The rest can remain terra incognito. The fact is, you don't need to be an anthropologist to put culture to work in your organization.

In short: the good news is that the cultural work of open science is centered on those aspects of culture that can be intentionally described, discussed, and refactored-even if some of these might later become routine and get framed as default expectations. It's not a bad thing to have your active culture also inform the tacit level of culture, it's actually a goal: norms are cultural behaviors and attitudes that have become tacit culture. A norm is when "we open scientists do things like this," and think: why would we do anything else?

\section{Culture: trimmed down to size for the open scientist}

Here we will trim the semantic tangle of the term "culture" to a more specific notion of culture: to the point where it can serve our understanding of how this works and how this fits into the future of the academy. The word "culture" will still hold all of its diverse and multiplex meanings everywhere else, however, here we'll just agree to use 
it in one specific way to cut through a lot of the semantic shrubbery it has acquired over the centuries and around the globe.

\section{Learning from anthropology}

We can start by looking at some general attributes of "culture." In his 1993 book, Culture, Chris Jenks notes (following Ralph Parsons):

“...for present purposes three prominent keynotes of the discussion [around culture] may be picked out: first, that culture is transmitted, it constitutes a heritage or a social tradition; secondly, that it is learned, it is not a manifestation, in particular content, of man's genetic constitution; and third, that it is shared. Culture, that is, is on the one hand the product of, on the other hand a determinant of, systems of human social interaction" (Jenks 1993: 59).

Lets put these verbs into the following order: learn (first exposure) $\rightarrow$ share (locally) $\rightarrow$ transmit (across space/time). Repeat as needed. This sounds a lot like education, something the academy already does. For the individual, this process is, or can be, a lifelong activity. What Clifford Geertz reminds us is that these cultural activities are public. Nothing is cultural until it is shared. That means these activities are available to study, and to change, and to be changed through intentional intervention (although somewhat less available when they are only tacit).

One easy way to see what Jenks is proposing here is to substitute "language" for "culture;" after all, language is a good part of any society's cultural repertoire. Saying that language is transmitted is to acknowledge that we don't need to invent our own language anew every generation. Saying language is learned explains that we acquire this through learning as children and then hone this learning throughout our lives. To say that language is shared points to a key concept: we need others to make this work; it's called "conversation". In many ways, language is primarily a type of sharing. Other skills and cultural content exhibit these same features.

The reverse is also true. If a language is not transmitted over time it "dies". If a person doesn't learn a language, they are left outside the conversations that happen in that language. And when a language ceases to be shared in everyday life (e.g., it becomes a "sacred" language that can only be spoken in certain places/times), other language forms will take over in daily life. Languages change all the time. Remember that. They manifest lifelong, tacit cultural practices, and they still change.

Culture comes in community boxes 
"Community, therefore, is where one learns and continues to practice how to 'be social'. At the risk of substituting one indefinable category for another, we could say it is where one acquires 'culture'”' (Cohen 1985).

The usual container for a culture is called "community." As an organization grows and governs its own cultural work, you can say that the group becomes a community. You can dive into "community" elsewhere in the Handbook (See: on community). Notions of community will also be threaded into many of the Handbook chapters.

Meaning, Symbols, and Memes; oh my!

Exactly what is learned, transmitted, and shared as culture is complicated. "Meaning" usually pops up here, together with "symbols" (meaning carriers). In many ways anything that can be learned (anything you can get better at by learning this), and that must be shared in order to make sense as something to do (write a song, choose a new fashion statement, enter a conversation, sports, theatre, etc.) becomes culture when the various meanings of that learned behavior are also shared. You cannot have your own private culture. That said, you can have a very small community with its own distinguished cultural behaviors.

Memes are symbols that have been reimagined as cultural-genetic replicators. The analogy to biology is intentional, and meme theorists also talk of culture change as evolution. Since the 1970s, meme theories have been proposed to explain how certain cultural content packages spread and persist.

“[Richard] Dawkin's way of speaking was not meant to suggest that memes are conscious actors, only that they are entities with interests that can be furthered by natural selection. Their interests are not our interests. 'A meme,' [Daniel] Dennett says, 'is an information packet with attitude'"' (Gleick 2011).

The notion of a meme is centered on the idea that humans as social beings are shaped by culture the same way their bodies are shaped by their DNA. If you want to explore memes a bit more, here's a good introduction (by Dennett) and some good counter arguments (by Lanier). Here we will talk about meaning and symbols and culture change, but you are certainly free to talk about memes and evolution. You can also look into "cultural science," where evolutionary cultural studies are being done. 


\section{Culture is a plural noun}

Not grammatically, of course, but we have seen and continue to see around us how cultural notions, skills, and activities are typically multiple, contested, fragile, and liable to change. Individuals tend to privilege those notions, skills, and activities they have invested time to learn (so nobody wants to be forced to use a different language). However, since culture must be shared to be viable, individuals continually find themselves in conversation with others who have differing cultural inventories. Culture is like a life-long song we only sing once, and none of us has been handed the score for the next chorus. We just keep on singing, in multipart harmony.

Of course, culture is not only a noun. Humans are cultural beings. Humans have culture. Humans do culture. Science is a culture. Universities have organizational cultures. Culture is alive on the internet. There is a lot of culture going on all the time. More recent takes on organizational culture reject this as being just some packet of ideas that gets passed around. Today, more than ever before, culture is viral, active, flowing (Appadurai 1996).

\section{The cultural work of social organizations}

Cultural practices and social organizations are intertwined in time and space. Social organizations are the social "appliances," the furniture, that anchor human groups into more durable cultural contexts, which they support and are, in turn, supported by. These contexts expand our capacity for collective action, including economic and political action. Just as we do not need to-or get to-invent our own language, we don't get to invent most of the social groups we intersect in our lives. But we can change them.

In order to pursue the intrinsic cultural work of the academy, we build communities inside organizations that use governance processes to support sharing knowing. We use can our organizations to manage other, social and economic tasks. If knowing is a dance, then community is the dance floor, and the organization is the dance hall.

\section{The social work of cultural organizations}

While this section is about the work of culture, it is good to remember that culture informs the social work of organizations. Later in this section we will look at values, virtues, freedoms, and principles, and at strategies, norms, and rules. All of these translate cultural work into social settings and systems. In some ways, social systems are like petrified conversations: they take the result of discussions and turn them into procedures, work codes, job descriptions, organizational charts, accounting schemes, 
etc. The important work of culture in any organization is to keep the conversations current. This is how an organization learns, pivots, when needed, and reinvents itself.

In the twenty-five years since Jenks' book, culture has seen a lot of new attention. From the academic discipline of "cultural studies" to the cubicles of Silicon Valley startup companies, the importance of culture for the everyday life and future prospects of societies and corporations has become a central theme. It's high time for the academy to take a culture turn. You can help.

Now you know enough about the various aspects of culture to start rolling up your pants and wading in. You know that culture is (and must be) learned, shared, and transmitted. Most of culture is really vulnerable to intervention or substitution. Culture describes a broad range of human activities and a layer of meaning that is spread over (or under) social activities and organizations. The meanings of culture are all public. You can find them, interrogate them, and, yes, change them. That's the next topic in the Handbook: The task: culture change.

\section{Bibliography: Oppen Scientist Handbook References}

